\title{
UMA ANÁLISE DO DISCURSO POLÍTICO ESTUDANTIL DE CARINA VITRAL À LUZ DA LINGUÍSTICA SISTÊMICO-FUNCIONAL E DA ANÁLISE CRÍTICA DO DISCURSO
}

\author{
Jonathas da Silva Rosa ${ }^{1}$, Vilmar FerReira de SOUZA ${ }^{1}$, Ingrid MEndes de Lima Gomes ${ }^{1}$ \\ ${ }^{1}$ Instituto Federal de Educação, Ciência e Tecnologia do Ceará - IFCE \\ <jonathasrosa85@gmail.com><vilmardesouza@unilab.edu.br><ingridmendeeslg@gmail.com> \\ DOI: $10.21439 /$ conexoes.v12i2.1446
}

\begin{abstract}
Resumo. Este trabalho tem como objetivo analisar o discurso político estudantil para mostrar como Carina Vitral se representa e representa seus interlocutores no contexto dos últimos acontecimentos políticos no Brasil, tais como o impeachment da ex-presidente Dilma Rousseff, o governo do atual presidente Michel Temer, as prisões de membros do legislativo, a crise econômica do país e as manifestações populares que ocorreram nesse período. O trabalho se detém em analisar a construção discursiva da resistência estudantil em meio a esse novo quadro político. O corpus consiste de um texto, em língua portuguesa, publicado na página da website "Conversa afiada" escrito pela estudante de economia da PUC-SP - Carina Vitral, Ex-presidente da União Nacional dos Estudantes (UNE), página esta administrada pelo jornalista Paulo Henrique Amorim. A pesquisa utiliza como arcabouço teórico a Linguística Sistêmico-funcional de Halliday e Matthiessen (2014), a Análise Crítica do Discurso com base em Fairclough (2003) e o lugar do conceito de ideologia de DeSouza (2015). Da LSF utilizo o sistema de transitividade na descrição e interpretação linguística e da ACD, o conceito de ideologia. Os resultados obtidos com a análise em relação às categorias de transitividade mostraram duas macrofiguras. Na primeira, Carina Vitral é representada nos processos materiais como ator de resistência que faz frente ao governo vigente; na segunda, ela é representada nos processos relacionais, construindo uma relação dela com dois mundos opostos: o mundo do "nós" (UNE, ESTUDANTES E TRABALHADORES) e o mundo do "Eles" (GOVERNO).
\end{abstract}

Palavras-chaves: Linguística Sistêmico-Funcional; Análise Crítica do Discurso; Discurso Político Estudantil.

\begin{abstract}
This paper aims to analyze student political discourse to show how Carina Vitral represents herself and represents her interlocutors in her political discourse produced in the context of recent political events in Brazil, such as the impeachment of former President Dilma Rousseff, the government of the current president Michel Temer, the prisons of members of the legislature, the country's economic crisis and the popular demonstrations that took place during that period. The work focuses on analyzing the discursive construction of student resistance in the midst of this new political framework. The corpus consists of a text, in Portuguese, published on the page of the website "Conversa edia" written by the economics student of PUC-SP - Carina Vitral, former president of the National Union of Students (UNE), page managed by the journalist Paulo Henrique Amorim. The research uses as a theoretical framework the Systemic-functional Linguistics of Halliday and Matthiessen (2014), the Critical Discourse Analysis based on Fairclough (2003) and the place of the concept of ideology of DeSouza (2015). From LSF I use the system of transitivity in the description and interpretation of language and the ACD, the concept of ideology. The results obtained with the analysis in relation to the categories of transitivity showed two macrofigures. In the first, Carina Vitral is represented in the material processes as an actor of resistance who faces the current government; in the second, it is represented in the relational processes, constructing a relation of it with two opposing worlds: the world of "we" (UNE, STUDENTS AND WORKERS) and the world of "They" (GOVERNMENT).
\end{abstract}

Keywords: Systemic-Functional Grammar; Critical Discourse Analysis; Student Political Discourse. 


\section{INTRODUÇÃO}

A Linguística Sistêmico-Funcional (doravante, LSF) busca compreender a natureza e as funções da linguagem. Dentro desse mundo de possibilidades utilizo a lexicogramática da LSF para cumprir o objetivo deste trabalho que é analisar o discurso político estudantil para mostrar como Carina Vitral se representa e representa seus interlocutores em seu discurso político produzido no contexto dos últimos acontecimentos políticos no Brasil tais como o impeachment da ex-presidente Dilma Rousseff, o governo do atual presidente Michel Temer, as prisões de membros do legislativo, a crise econômica do país e as manifestações populares que ocorreram nesse período. Nesse contexto de instabilidade no país analisar o discurso que emerge do movimento estudantil é compreender o atual momento político brasileiro a partir dos enunciados que circulam em vários contextos sociais, pois a compreensão da língua e da sociedade são inseparáveis. Este trabalho é fruto de uma experiência com o movimento estudantil, quando participei do I CONEIFCE cujo tema foi "Os desafios do movimento estudantil". Os objetivos específicos deste trabalho são a) identificar quais processos são mais frequentes no discurso político estudantil de Carina Vitral e b) investigar como ela é representada linguística e discursivamente. O corpus consiste de um texto, em língua portuguesa, publicado na página da website administrada pelo jornalista Paulo Henrique Amorim "Conversa afiada". O texto foi escrito pela estudante de economia da PUC-SP - Carina Vitral, Ex-presidente da União Nacional dos Estudantes (UNE).

Desse modo, a organização do trabalho apresenta-se da seguinte forma: na seção 2, apresentamos os pressupostos teóricos que fundamentam o trabalho utilizando a teoria da LSF de Halliday e Matthiessen (2014), abordando especificamente a metafunção ideacional para a utilização do sistema de transitividade na análise dos textos propostos como corpus e a Análise Crítica do Discurso de Fairclough (2003), utilizando o conceito de ideologia; na seção 3 trazemos o percurso metodológico, na seção 4 a apresentação dos resultados e na seção 5, algumas considerações finais sobre este trabalho.

\section{A LINGUÍSTICA SISTÊMICO-FUNCIONAL}

A Linguística Sistêmico-Funcional tem sido utilizada para investigar diversos fenômenos linguísticos como marcas linguísticas de poder (DESOUZA, 2011), as marcas linguísticas de interpessoalidade (Cabral, 2016), desenvolvimento da segunda língua (Praxedes Filho.
2007) entre outros.

A partir do início da década de 60, M.A.K. Halliday começa a desenvolver uma teoria linguística que culmina com sua primeira publicação denominada "Gramatica de Escalas e Categorias". A abordagem de língua adotada por ele é como um sistema sóciossemiótico formado por um potencial de recursos, de significados, de formas e expressões, assim o aspecto sistêmico da teoria se dá a partir de um leque de escolhas que o usuário tem disponíveis, ou seja, a língua é organizada paradigmaticamente. $\mathrm{O}$ aspecto funcional da LSF, por sua vez, se dá através da realização das escolhas feitas pelo usuário no sistema linguístico por meio de estruturas composta por uma sequência de constituintes funcionais; ou seja o aspecto sintagmático da língua é consequência de seu aspecto paradigmático.

Para Halliday e Matthiessen (2014), a língua é um sistema de escolhas que são realizadas estruturalmente, sendo dessa forma estratificada. Ele a divide nos estratos fonético, fonológico, lexicogramático, semântico e contextos. A razão pela qual a língua é estratificada se dá por ela ser uma semiose e para que haja a construção de significados via signos, esta tem que ser estratificada, com os estratos se relacionando por realização-ativação e realização-construção. E deste modo o texto é o resultado de escolhas realizadas em redes de sistemas, justificando assim, o termo "sistêmico-funcional" de sua gramática.

A estrutura gramatical, portanto, é uma parte essencial da língua, porém apenas realiza as escolhas. Quando analisamos um texto, estamos mostrando os resultados das escolhas realizadas na estrutura de cada oração do texto. Essas escolhas são significativas porque foram feitas em relação ao que poderia ter sido escolhido.

As escolhas que o usuário faz no estrato intralinguístico são acionadas por elementos extralinguísticos do contexto, ou seja, o contexto de situação e o contexto de cultura. Para Malinowski (1923), o contexto de cultura consiste em como as diferentes culturas utilizam a língua e o que os membros de uma comunidade podem significar em termos culturais. Interpretamos a cultura como um sistema de significados de nível superior como um meio de significados em que operam vários sistemas semióticos, incluindo linguagem verbal e não verbal.

De acordo com Halliday e Matthiessen (2014), o contexto de situação abrange a atividade social, as pessoas envolvidas nessa atividade e as funções especificas atribuídas ao texto dentro dele, assim, quaisquer tipos de situação podem ser caracterizados em campo, rela- 
UMA ANÁLISE DO DISCURSO POLÍTICO ESTUDANTIL DE CARINA VITRAL À LUZ DA LINGUÍSTICA SISTÊMICO-FUNCIONAL E DA ANÁLISE CRÍTICA DO DISCURSO

ções e modo. O Campo é o que está acontecendo na situação; é a natureza da atividade social, semiótica e o domínio de experiência que esta atividade relaciona, ou seja, o "assunto", o "tópico". As Relações são os papéis desempenhados por aqueles que participam da atividade sóciossemiótica e o Modo é o papel que a língua está desempenhando e outros sistemas semióticos na situação.

As funções que as línguas desempenham estão intricicamente relacionadas às três variáveis do contexto de situação, a saber: campo, relações e modo que Halliday e Matthiessen (2014) intitulam de metafunções. De acordo com Fuzer e Cabral (2014) "as metafunções são as manifestações, no sistema linguístico, dos propósitos que estão subjacentes a todos os usos da língua”. Assim temos a metafunção ideacional que agrega significados experienciais e lógicos; a metafunção interpessoal que envolve os significados que expressam a interação entre participantes de uma comunicação e a metafunção textual fornece a construção coesa e coerente nos textos. Essas três metafunções estão alinhadas com as três variáveis do contexto de situação como mostra a Figura 1 abaixo:

\begin{tabular}{|c|c|}
\hline Variáveis do contexto de Situação & Metafunções das Línguas \\
\hline Campo & Ideacional \\
\hline Relações & Interperssoal \\
\hline Modo & Textual \\
\hline
\end{tabular}

Figura 1: Variáveis do contexto de situação e metafunções Fonte: Adaptada de Fuzer e Cabral (2014, p. 32).

Essas três metafunções, localizadas no estrato da semântica, são a base para a análise de como os significados são construídos e entendidos e sua relação com três tipos de estruturas. O estrato lexicogramátical é constituído pelo menos de três sistemas, a saber: o sistema de transitividade, o sistema modo e modalidade e o sistema de tema, representados na Figura 02 abaixo:

\begin{tabular}{|c|c|}
\hline Metafunção das línguas & Sistemas lexicogramáticos \\
\hline Ideacional & transitividade \\
\hline Interpessoal & modo e modalidade \\
\hline Textual & tema \\
\hline
\end{tabular}

Figura 2: Metafunções das línguas

Fonte: Adaptada de Halliday e Mathiessen (2014).

Segundo Halliday e Matthiessen(2014), instanciação é outro conceito que consiste em uma escala de generalização que diz respeito a configuração de padrões probabilísticos de recursos linguísticos que medeiam a relação contínua entre língua como potencial (sistema) de um lado, e língua como instância (texto) de outro. $\mathrm{Na}$ perspectiva sistêmico-funcional, a instanciação da língua é compreendida e predisposta às interferências do contexto, assim quando fazemos determinadas escolhas linguísticas levamos em conta os contextos de cultura e de situação nos quais estamos inseridos.

Outra forma de entendermos o funcionamento das metafunções de forma estratificada é em um quadro elaborado no grupo de pesquisa de Gramática SistêmicoFuncional (GSF) e da Análise Crítica do Discurso (ACD) - Sertões de Crateús, mostrado na Figura 3 a seguir:

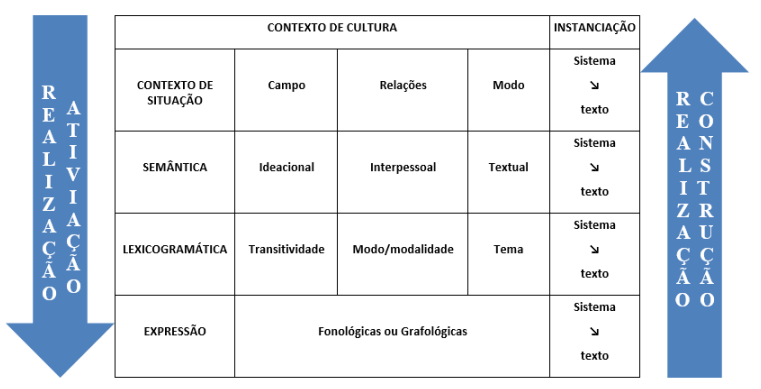

Figura 3: Sistema de estratificação da linguagem

Fonte: Quadro criado pelo grupo de pesquisa Gramática SistêmicoFuncional e Análise Crítica do Discurso - Sertões de Crateús

Cada estrato se comunica uns com os outros através de uma relação de realização. Esse tipo de relação significa que um estrato realiza outro superior que é realizado por um inferior. Assim cada sistema na lexicogramática realiza uma das três metafunções, as quais realizam as três variáveis do contexto de situação, que por sua vez são realizações possíveis do contexto de cultura.

A variável do contexto de situação Campo é realizada no estrato semântico pela metafunção ideacional, que por sua vez, é realizado no estrato lexicogramático pelo sistema de transitividade, que ativa ou é realizada pelas escolhas no estrato de expressões fonológicas ou grafológicas. Do mesmo modo, a variável do contexto de situação Relações é realizada por escolhas de significados interpessoais, que, no estrato lexicogramatical, são realizados pelo sistema de modo e modalidade, que é realizado no estrato de expressão através de textos escritos ou orais. Por fim, a variável de contexto de situação Modo é realizada pelos significados textuais, que, por sua vez são realizados pelo sistema de tema, no estrato lexicogramátical, que é realizado no estrado de expressão. 


\subsection{O Sistema de Transitividade}

Os falantes, em seus textos, representam suas experiências do mundo externo ou do mundo interno, porque a metafunção ideacional-experiencial nos habilita a representarmos nossas experiências e os significados representacionais são realizados pelo sistema lexicogramátical de transitividade. Os processos assim como os participantes e as circunstâncias do evento comunicativo são os constituintes funcionais da oração segundo sistema de transitividade que permite representar o que está acontecendo, quem faz o quê a quem, onde, quando, como e porquê. Combinando essas categorias temos a figura 04 representativa deste sistema.

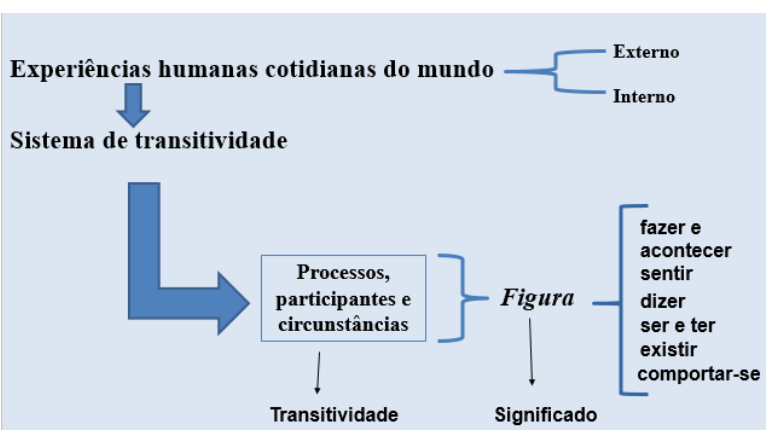

Figura 4: Sistema de transitividade Fonte: Adaptada de Fuzer e Cabral (2014 p. 41)

A transitividade é um sistema de relações que representa um bloco de significação dentro de uma determinada ação comunicativa. Os processos propostos por Halliday e Matthiessen (2014) são divididos em primários - que são os materiais, os mentais e os relacionais, e os secundários - os comportamentais, verbais e existenciais, representados na figura 05 .

Os processos materiais descrevem ações representadas em orações com aspectos de fazer e acontecer mostrando mudanças concretas do mundo. Os participantes se definem como seguem: Ator - o que faz a ação, Meta - coisa afetada pela ação, Extensão - coisa não afetada pela ação e o Beneficiário da ação. Exemplo utilizado do corpus:

\begin{tabular}{|c|l|l|l|l|l|}
\hline \multirow{2}{*}{27} & Já lutamos & $\begin{array}{l}\text { na democracia } \\
\text { e fora dela, }\end{array}$ & já fizemos & isso & $\begin{array}{l}\text { sob perseguiç̃o, na } \\
\text { clandestinidade... }\end{array}$ \\
\cline { 2 - 6 } & Proc. Material & $\begin{array}{l}\text { Circunstância de } \\
\text { localização/lugar }\end{array}$ & Proc. Material & Meta & Circunstância \\
\hline
\end{tabular}

Os processos mentais descrevem nossas experiências do mundo interno, seus tipos são cognitivos, perceptivos, desiderativos e emotivos, o participante é o Experienciador (que normalmente é humano) enquanto que o Fenômeno é aquilo que é pensado, desejado e percebido. Exemplo utilizado do corpus:

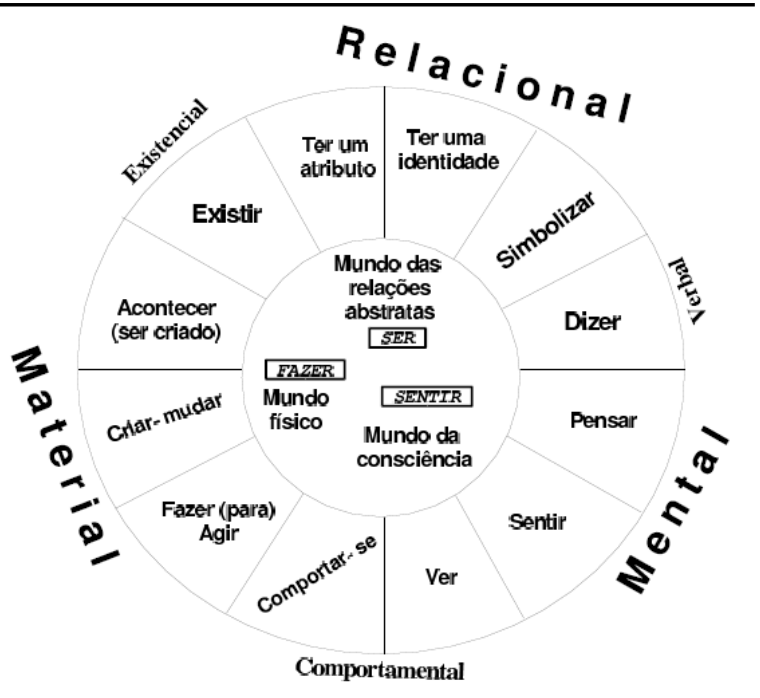

Figura 5: Tipos de processos

Fonte: Adaptada de Lima-Lopes (2001, p. 9)

\begin{tabular}{|c|l|l|l|l|l|}
\hline \multirow{4}{*}{23} & Enganam & -se, & no entanto, se & {$[$ Eles = $\oslash]$} & acham \\
\cline { 2 - 6 } & Proc. Mental & Beneficiário & $\begin{array}{l}\text { Elemento } \\
\text { Interpessoal }\end{array}$ & Experienciador & Proc. Mental \\
\cline { 2 - 6 } & que & Eles $=\varnothing]$ & avançarão & sem resistência. \\
\cline { 2 - 6 } & $\begin{array}{l}\text { Elemento } \\
\text { Interpessoal }\end{array}$ & Ator & Proc. material & Circunstância \\
\hline
\end{tabular}

Os processos relacionais indicam uma relação entre dois participantes podendo ser de identificação ou de atributos. Nas orações identificativas o participante é o Identificado e o outro elemento é o Identificador, uma Característica ou um Valor. É nos processos relacionais atributivos que existe um Portador e um Atributo. Exemplo utilizado do corpus:

\begin{tabular}{|c|l|l|l|l|l|}
\hline 12 & $\begin{array}{l}\text { A tentativa } \\
\text { de desmanche }\end{array}$ & é & $\begin{array}{l}\text { rápida, radical } \\
\text { e arbitrária, }\end{array}$ & pois os golpistas & sabem \\
\cline { 2 - 6 } & Portador & $\begin{array}{l}\text { Proc. } \\
\text { Relacional }\end{array}$ & Atributo & Experienciador & Proc. Mental \\
\cline { 4 - 6 } & \multirow{2}{*}{ que } & são & medidas que & não seriam & $\begin{array}{l}\text { aprovadas } \\
\text { pelas urnas } \\
\text { e a opinaão } \\
\text { pública. }\end{array}$ \\
\cline { 2 - 6 } & $\begin{array}{l}\text { Elemento } \\
\text { textual }\end{array}$ & $\begin{array}{l}\text { Proc. } \\
\text { Relacional }\end{array}$ & Identificador & $\begin{array}{l}\text { Proc. } \\
\text { Relacional }\end{array}$ & Atributo \\
\cline { 2 - 6 } \\
\cline { 2 - 5 }
\end{tabular}

Os processos comportamentais descrevem processos fisiológicos e psicológicos, situando-se entre os processos materiais e mentais. Eles não representam uma ação, mas o seu significado pode levar a uma ou mais ações. O participante é o Comportante consciente. No corpus não tem ocorrência deste tipo de processo, por isso, utilizamos um exemplo de outro texto da autora.

Os processos verbais expressam "qualquer troca simbólica de significados" (Halliday, 1994, p.140) o dizer e todos os seus sinônimos incluindo outros verbos do mesmo campo semântico. O participante é o $D i$ zente que é o próprio falante, enquanto que o Receptor 
UMA ANÁLISE DO DISCURSO POLÍTICO ESTUDANTIL DE CARINA VITRAL À LUZ DA LINGUÍSTICA SISTÊMICO-FUNCIONAL E DA ANÁLISE CRÍTICA DO DISCURSO

\begin{tabular}{|l|l|l|l|}
\hline $\begin{array}{l}\text { Cabe a tristeza } \\
\text { enorme de }\end{array}$ & acompanhar, & $\begin{array}{l}\text { cinquenta } \\
\text { anos depois, }\end{array}$ & $\begin{array}{l}\text { um golpe de Estado } \\
\text { seguido dos ataques, }\end{array}$ \\
\hline Comportamento & $\begin{array}{l}\text { Processo } \\
\text { Comportamental }\end{array}$ & $\begin{array}{l}\text { Circunstância } \\
\text { de Tempo }\end{array}$ & Circunstância \\
\hline justamente, & aos jovens & que se mobilizam & pela democracia. \\
\hline $\begin{array}{l}\text { Elemento } \\
\text { Interpessoal }\end{array}$ & Ator & Processo material & Meta \\
\hline
\end{tabular}

é o participante a quem é dirigido o discurso em que o Alvo é a entidade atingida pelo processo de dizer e a Verbiagem que é o dito. Exemplo utilizado do corpus:

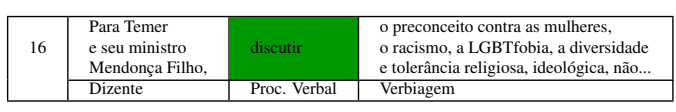

Os processos existenciais são orações que representam algo que existe, apresentado em um pequeno número de discursos, implicando em apenas um participante - o Existente, de ocorrência obrigatória que pode ser algo material, um fenômeno ou um evento. Exemplo utilizado do corpus:

\begin{tabular}{|c|l|l|l|l|}
\hline \multirow{3}{*}{25} & \multirow{2}{*}{ E se } & \multicolumn{2}{|l|}{ há } & $\begin{array}{l}\text { algo que a }{ }^{1} \text { [juventude] } \\
\text { brasileira }\end{array}$ \\
\cline { 2 - 5 } & Elemento Interpessoal & \multicolumn{2}{|l|}{ Proc. Existencial } & Existente/ ${ }^{1}$ Ator \\
\cline { 2 - 4 } & vai fazer & é & defender & o seu legado. \\
\cline { 2 - 5 } & Proc. Material & Proc. Relacional & Proc. Verbal & Alvo \\
\cline { 2 - 4 } & Meta & \\
\hline
\end{tabular}

Um sistema lexicogramático é constituído por escolhas lexicogramaticais, as quais, por sua vez são realizadas por constituintes funcionais da oração, ou seja oração como representação. As escolhas no sistema de transitividade além de serem realizadas pelos constituintes Processos e Participantes, são também realizadas por circunstancias. Halliday e Matthiessen (2004) estabelecem a noção de circunstância a partir de três considerações: a) elas são expressas por grupos adverbiais ou frases preposicionais, raramente por grupos nominais; b) por circunstâncias de localização de um evento no tempo e no espaço, causa de um evento ou ainda por noções como onde, quando e como; c) enquanto os participantes correspondem ao sujeito ou complemento, as circunstancias correspondem aos adjuntos. A Figura 06 relaciona os tipos de circunstâncias e seus subtipos.

\subsection{A ANÁLISE CRÍTICA DO DISCURSO}

É sob o horizonte do marxismo e de um momento de crescimento linguístico que nasce o projeto da Análise do Discurso com um objetivo político e linguístico de compreender os movimentos políticos sociais. Zellig S. Harris foi o primeiro teórico a utilizar a expressão Análise do Discurso.

Entretanto, concebida como uma proposta de continuidade, emerge a Análise Crítica do Discurso, oriunda

\begin{tabular}{|c|c|}
\hline \multicolumn{2}{|c|}{ CIRCUNSTÂNCIAS } \\
\hline \multirow{2}{*}{ Extensão } & Distância \\
\cline { 2 - 2 } & Duração \\
\cline { 2 - 2 } & Frequência \\
\hline Localização & Lugar \\
\cline { 2 - 2 } & Tempo \\
\hline \multirow{2}{*}{ Modo } & Meio \\
\cline { 2 - 2 } & Qualidade \\
\cline { 2 - 2 } Causa & Comparação \\
\cline { 2 - 2 } & Razão \\
\hline \multirow{2}{*}{ Contingência } & Condição \\
\cline { 2 - 2 } & Concessão \\
\hline Acompanhamento \\
\hline \multicolumn{2}{|c|}{ Papel } \\
\hline
\end{tabular}

Figura 6: Tipos de circunstâncias e seus subtipos Adaptada de Halliday e Matthiessen (2004, p 206-263).

de uma linguística crítica no início de 1990, após um simpósio em Amsterdã. A ACD é uma abordagem transdisciplinar teórico-metodológica que se vale da compreensão da língua relacionada a uma problematização da vida social.

O princípio que norteia a pesquisa na ACD é a investigação de problemas de cunho sociodiscursivos, trabalhando a língua no interior do social. Gunther Kress e Norman Fairclough foram os pesquisadores que tiveram participação fundamental na criação dessa linha de estudo, ambos professores na Inglaterra, desenvolvendo uma abordagem que toma o uso da língua como uma forma de prática social, visando investigar as mudanças sociais e culturais que tem tido profundo impacto na vida social contemporânea desde seu surgimento.

A ACD parte da análise do texto para estudar as interações sociais se inserindo no limite entre dois pontos: a) um puramente sociológico e b) um puramente linguístico. No limite entre esses pontos, busca relacionar o elemento língua com o elemento social.

De acordo com Van Dick (2001), a ACD é uma vertente que estuda a forma como o abuso, o domínio e a desigualdade de poder social são estabelecidos, reproduzidos e mantidos através do discurso em um contexto sociopolítico.

Essa correlação entre elementos linguísticos e nãolinguísticos tem sido o cerne do percurso da Análise Crítica do Discurso desde o seu início. Para Harris 
UMA ANÁLISE DO DISCURSO POLÍTICO ESTUDANTIL DE CARINA VITRAL À LUZ DA LINGUÍSTICA SISTÊMICO-FUNCIONAL E DA ANÁLISE CRÍTICA DO DISCURSO

(1952), a ACD significa "linguística descritiva além dos limites de uma única frase"e vincula elementos culturais e linguísticos.

\subsubsection{O Lugar do Conceito de Ideologia na ACD}

As ideologias e outras representações sociais controlam o discurso e outras práticas sociais dos membros do grupo. Elas são capazes de fazer isso somente quando suas propriedades naturais e abstratas também se aplicam em situações, atores, ações e eventos de maneira específica. Assim, além da psicologia social das crenças grupais também precisamos de uma psicologia individual de crenças e experiências pessoais, nomeadamente as de atores sociais individuais. O discurso político pode expressar ideologias de grupo como também outras crenças, especialmente em formas coletivas de texto ou conversa.

Assim, enquanto a natureza social das ideologias é definida por sistemas de crença compartilhados por grupos sociais que são usados pelos membros do grupo, a expressão, aquisição e reprodução de ideologias ocorrem em situações específicas de comunicação social. Fairclough (2003) define ideologia como "uma concepção do mundo que é implicitamente manifesta na arte, na lei, da atividade econômica em todas as manifestações da vida individual e coletiva".

Fairclough (2003) no seu modelo tridimensional centraliza o conceito de ideologia, assim como Van Dijk (1998), no campo da linguística cognitiva, discordando da abordagem negativa que o conceito tinha no materialismo histórico de Karl Marx e Frederic Engels. DeSouza (2015) mostra a mudança de abordagem do conceito de ideologia elencando características que o transpassam. Uma delas é que "a ideologia constitui assim delimitada, um conceito multiestratal, não podendo, por isso mesmo, ser estudada por nenhuma perspectiva em particular.". Por isso, afirma que as dimensões: a) antropológica; b) politica; c) social; d) religiosa e) histórica e f) semiótico-discursiva podem construir aspectos de uma teoria da ideologia. A figura a seguir mostra a representação gráfica do conceito de ideologia.

A Figura mostra, na vida material e social, a manifestação discursiva da ideologia observada em práticas sociais, seja elas quais forem, ocorrendo de forma simultânea em todos os níveis mostrados. Esse modelo analítico discursivo contribuiu para a pesquisa desenvolvida em DeSouza (2011a) que investigou as relações de poder do discurso político de Padre Cícero.

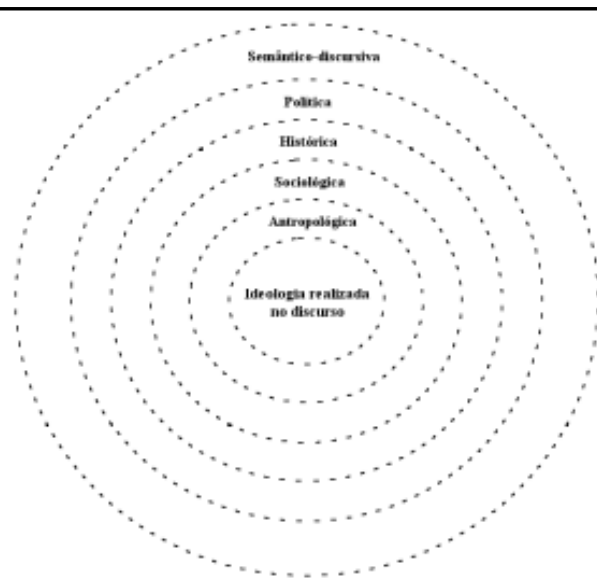

Figura 7: A representação gráfica do conceito de ideologia Adaptada de Elaborada em DeSouza (2011a)

\subsubsection{O Discurso Político da UNE}

A definição de Discurso Político aqui utilizada alinha-se com a de Van Dijk (1997) quando define que o discurso político "é identificado por seus atores ou autores, a saber, políticos". No entanto, ele afirma em seu texto "What is Political Discourse Analysis?" que os políticos não são os únicos participantes no domínio da política. Devemos também incluir os vários destinatários em eventos comunicativos políticos, como o público, as pessoas, os cidadãos e outros grupos ou categorias.

Essa abordagem se justifica aqui porque amplia o discurso político para uma esfera que ultrapassa a política oficial e profissional existente no meio público, assim o discurso político estudantil de Carina Vitral corresponde ao grupo de manifestantes e dissidentes.

$\mathrm{O}$ discurso político não se trata de um gênero, mas de uma classe de gêneros definidos por um domínio social. Assim, as deliberações governamentais, os debates parlamentares, os programas partidários e os discursos dos políticos estão entre os muitos gêneros que pertencem ao domínio da política. Isso significa que uma conversa informal de um político com seus amigos não conta como um discurso político; o discurso deve ser produzido pelo falante em seu papel profissional de político e em um ambiente institucional.

Van Dijk (1998) afirma que na verdade o discurso político é eminentemente ideológico, isso significa que se nos concentrarmos nos políticos, podemos ter pelo menos duas ideologias expressadas em seus textos e conversas: ideologias profissionais, que subjazem seu funcionamento como políticos e as ideologias sociopolíticas que aderem, por exemplo, como membros de par- 
UMA ANÁLISE DO DISCURSO POLÍTICO ESTUDANTIL DE CARINA VITRAL À LUZ DA LINGUÍSTICA SISTÊMICO-FUNCIONAL E DA ANÁLISE CRÍTICA DO DISCURSO

tidos políticos ou grupos sociais. Temos, portanto, políticos conservadores e progressistas, socialistas e neoliberais, cristão-democratas, nacionalistas e racistas e outros. É provável que essas ideologias apareçam e se combinem no discurso dos políticos assim como no discurso político estudantil.

Outra questão a se considerar é o mundo discursivo correspondente a posturas conhecidas como 'Esquerda e Direita', termos estes abordados por Bobbio (1995), pelas quais o posicionamento ideológico busca por reformas. Todavia, há diferenças de causas entre eles. A esquerda busca promover justiça social, enquanto que a direita luta por uma liberdade individual.

O discurso político de Carina Vitral representava a União Nacional dos Estudantes - UNE que foi fundada em 1937 surgindo como resultado de um grande movimento estudantil em defesa da criação de uma entidade que agregasse todos os estudantes universitários na discussão de questões nacionais.

Taveira (2013) afirma que a movimentação política da UNE demonstra o interesse da entidade pela vida política do país e seu envolvimento constante na discussão dos problemas nacionais. A UNE participou e continua participando intensamente dos acontecimentos políticos ocorridos no Brasil em períodos marcados pela tensão e pela insegurança institucional.

Assim, esses alunos passam a representar um eficiente canal de expressão das reivindicações sociais e políticas, significando um novo fator cultural em sua sociedade e ganhando uma forte representatividade.

\section{PERCURSO METODOLÓGICO}

Para analisar o discurso político estudantil de Carina Vitral e mostrar como ela se representa e representa seus interlocutores no contexto dos últimos acontecimentos políticos no Brasil utilizamos o sistema de transitividade do estrato lexicogramático da LSF. O corpus consiste de um texto, em língua portuguesa, publicado na página da website "Conversa afiada", administrada pelo jornalista Paulo Henrique Amorim. Nas subseções que seguem descrevemos como se deu a seleção do corpus e os procedimentos de análise do texto.

\subsection{Seleção do corpus}

Definida a temática desta pesquisa, que é analisar o discurso político estudantil produzido no contexto dos últimos acontecimentos políticos no Brasil, e entendendo que a União Nacional dos Estudantes (UNE) é a instituição que representa os estudantes das universidades do Brasil, buscamos um texto em língua por- tuguesa da ex- presidente da UNE - Carina Vitral, estudante de economia da PUC-SP. Utilizamos o site de pesquisa Google como veículo para a busca do texto, que nos direcionou a vários links e optamos por utilizar a página da website "Conversa afiada", no qual Carina Vitral é colunista. A página é administrada pelo jornalista Paulo Henrique Amorim. O texto foi escolhido por sua ligação direta com os últimos acontecimentos políticos no Brasil e por ser o primeiro texto publicado na coluna. O título e a data de publicação do texto escolhido seguem nas figuras 08 .

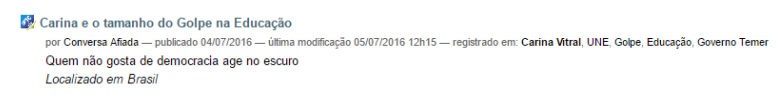

Figura 8: Título e data de publicação do texto.

Definido o texto, partimos para os procedimentos de análise linguística utilizando o sistema de transitividade do estrato lexicogramático da Linguística SistêmicoFuncional de Halliday e Matthiessen (2014).

\subsection{Procedimentos de análise}

Primeiramente, separamos um texto em complexos oracionais, cada complexo oracional foi devidamente numerado; em seguida, utilizamos o sistema de transitividade de Halliday e Matthiessen (2014) para categorizar as orações como consta no Anexo desse artigo. Uma vez que todas as orações dos complexos oracionais do texto foram devidamente categorizadas pelo sistema de transitividade, passamos a interpretar os dados. Primeiramente, verificamos qual processo é mais proeminente. Após contabilizados de forma manual, buscamos mostrar os padrões de língua no sistema de transitividade para o propósito comunicativo do texto.

Ao final, através dos dados obtidos, desvelamos a representação da resistência política estudantil, utilizando o discurso de Carina Vitral como prática social.

\section{RESULTADOS E DISCUSSÃO}

$\mathrm{Na}$ análise dos textos foram encontrados trinta e três (33) complexos oracionais, dos quais, cinco (5) apresentam transitividade incompleta pela ausência de processos. Foram identificados setenta e um (71) processos nas orações que compõem os complexos oracionais, mostrados no gráfico a seguir:

Como podemos observar no gráfico acima, os processos são em sua grande maioria, materiais e relacionais, o que nos diz que há uma forte tendência do discurso político estudantil materializado no texto do corpus desta pesquisa de representar "ações concretas" e 


\section{GRÁFICO DOS PROCESSOS ENCONTRADOS NA ANÁLISE}

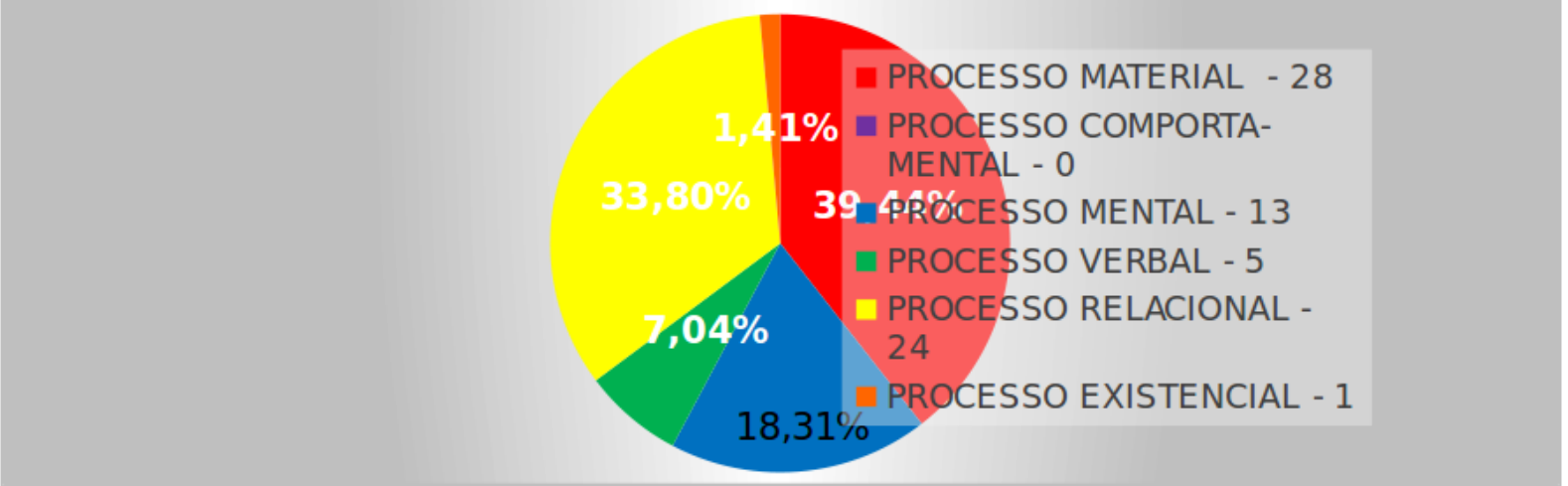

"relações de participantes", que são as características básicas destes tipos de processos.

Ao investigarmos essas proeminências percebemos que dos vinte e oito (28) processos materiais que Carina Vitral utiliza, cinco (5) são como participante Ator (Eu/Nós) da ação. Dado o conteúdo semântico das ações é possível inferir que este "Nós" refere-se ao grupo de resistência que tem como principal representante a própria Carina Vitral, grupo este que faz frente ao governo vigente. Exemplo disso são as orações do complexo oracional que segue:

\begin{tabular}{|l|l|l|l|l|l|l|l|}
\hline 26 & [Nós= $\oslash]$ & Já fizemos & isso & $\begin{array}{l}\text { em diversos } \\
\text { outros } \\
\text { momentos } \\
\text { da história e }\end{array}$ & [Nós= $]$ & faremos & $\begin{array}{l}\text { em quantos } \\
\text { forem } \\
\text { precisos. }\end{array}$ \\
\cline { 2 - 7 } & Ator & $\begin{array}{l}\text { Processo } \\
\text { Material }\end{array}$ & Meta & $\begin{array}{l}\text { Circunstância } \\
\text { de tempo }\end{array}$ & Ator & $\begin{array}{l}\text { Processo } \\
\text { Material }\end{array}$ & Circunstância \\
\hline
\end{tabular}

Os processos descritos aqui, claramente, só podem ser realizados pelo grupo de resistência ao governo. Podemos inferir, então, que Carina Vitral se inclui como participante da resistência.

Notemos que em outras partes do texto, Carina Vitral utiliza 12 processos materiais correspondentes ao "governo", figurando-o como causador de ataques a alguns segmentos da sociedade como estudantes e trabalhadores, que não se beneficiam das medidas e reformas utilizadas pelo governo. Exemplo encontrado nas orações do complexo oracional a seguir:

\begin{tabular}{|l|l|l|l|l|}
\hline 9 & $\begin{array}{l}\text { O golpe sobre } \\
\text { o ensino do país já }\end{array}$ & prepara & $\begin{array}{l}\text { um cadáver de peso: } \\
\text { o PlanoNacional de } \\
\text { Educação (PNE), }\end{array}$ & aprovado \\
\cline { 2 - 5 } & Ator & Proc. Material & Meta/ Ator & Proc. Mental \\
\hline \multirow{2}{*}{ em 2014 e que } & está sendo & enterrado & $\begin{array}{l}\text { pela equipe dos } \\
\text { homens brancos } \\
\text { do não presidente. }\end{array}$ \\
\cline { 2 - 5 } & Circunstância de tempo & Proc. Relacional & Proc. Material & Ator \\
\hline
\end{tabular}

Estes processos materiais cumprem uma função bastante explorada no discurso de Carina Vitral junto à nação brasileira, que é o de apresentar estas medidas que o governo tomou segundo seu plano de governo.

Utilizando 4 processos materiais instiga a população a lutar contra os golpes que o governo implanta e mais 4 processos materiais para mostrar que os principais beneficiários, nesse cenário, são os empresários de ensino privado, como mostram os complexos oracionais abaixo:

\begin{tabular}{|l|l|l|l|l|l|}
\hline 29 & É & hora & de & preparar & $\begin{array}{l}\text { a nossa } \\
\text { contra-ofensiva. }\end{array}$ \\
\cline { 2 - 6 } & $\begin{array}{l}\text { Proc. } \\
\text { Relacional }\end{array}$ & Atributo & $\begin{array}{l}\text { Elemento } \\
\text { textual }\end{array}$ & $\begin{array}{l}\text { Proc. } \\
\text { Material }\end{array}$ & Meta \\
\hline
\end{tabular}

\begin{tabular}{|l|l|l|l|l|}
\hline 20 & $\begin{array}{l}\text { A recente fusão dos } \\
\text { grupos Kroton e Estácio, }\end{array}$ & criando & $\begin{array}{l}\text { uma nova gigante de } \\
\text { R\$5,5 bilhões no } \\
\text { mercado educacional, }\end{array}$ & demonstra \\
\cline { 2 - 6 } & Dizente & $\begin{array}{l}\text { Proc. } \\
\text { Material }\end{array}$ & Meta & Proc. Verbal \\
\hline $\begin{array}{l}\text { que a } \\
\text { perspectiva }\end{array}$ & é & de & Lucrar & $\begin{array}{l}\text { de forma diretamente } \\
\text { proporcional ao sucesso } \\
\text { do golpe. }\end{array}$ \\
\cline { 2 - 6 } Portador & $\begin{array}{l}\text { Proc. } \\
\text { Relacional }\end{array}$ & $\begin{array}{l}\text { Elemento } \\
\text { textual }\end{array}$ & Proc. Material & Circunstância \\
\hline
\end{tabular}

A macrofigura que emerge dos processos materiais no discurso de Carina Vitral é aquela de um mundo das ações concretas que abarca o avanço das medidas do governo a representando como ator de resistência que faz frente a esse governo vigente.

Os processos relacionais estabelecem uma relação entre dois mundos diferentes. No discurso político de Carina vitral, os processos relacionais constituem $34 \%$ do corpus (24 processos). Estes processos são realizados pelos verbos ser, estar, ter dentre outros encontrados ao longo do texto.

Isto confirma que Carina Vitral está demonstrando suas relações com os estudantes e com o governo brasi- 
UMA ANÁLISE DO DISCURSO POLÍTICO ESTUDANTIL DE CARINA VITRAL À LUZ DA LINGUÍSTICA SISTÊMICO-FUNCIONAL E DA ANÁLISE CRÍTICA DO DISCURSO

leiro, emergindo duas figuras de representação. A primeira é o mundo do "nós" que é formado por estudantes e a população brasileira com o intuito de fortalecer a resistência já criada ao longo de anos de lutas, como na oração do complexo oracional abaixo:

\begin{tabular}{|l|l|l|l|l|}
\hline 27 & Já lutamos & $\begin{array}{l}\text { na democracia } \\
\text { e fora dela, }\end{array}$ & já fizemos & isso \\
\cline { 2 - 5 } & Proc. Material & Circunstância & Proc. Material & Meta \\
\cline { 2 - 5 } & $\begin{array}{l}\text { sob perseguição, } \\
\text { na clandestinidade, }\end{array}$ & já fomos & $\begin{array}{l}\text { presos, torturados, } \\
\text { assassinados e nunca }\end{array}$ & desistimos. \\
\cline { 2 - 5 } & Circunstância & Proc. Relacional & Identificado & Proc. Mental \\
\hline
\end{tabular}

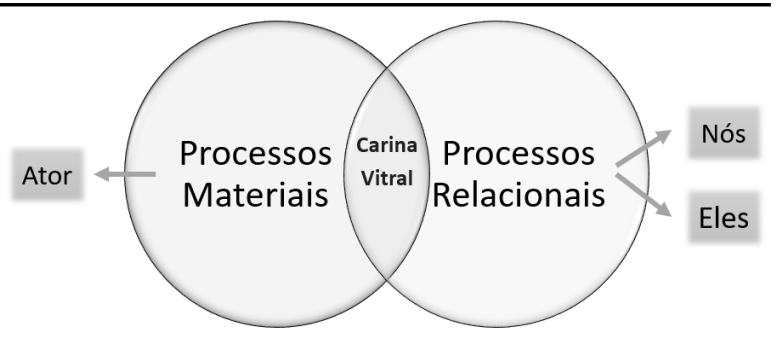

Figura 9: REPRESENTAÇÃO VISUAL DAS DUAS MACROFIGURAS

A segunda figura representativa assume outro mundo, o mundo do "eles" quando Carina Vitral referese ao governo com rejeição e reprovação a determinadas atitudes, como apresenta a oração do complexo oracional a seguir:

\begin{tabular}{|l|l|l|l|l|}
\hline 21 & São & os que & querem & $\begin{array}{l}\text { a educação como } \\
\text { mercadoria e não } \\
\text { como direito. }\end{array}$ \\
\cline { 2 - 4 } & $\begin{array}{l}\text { Processo } \\
\text { Relacional }\end{array}$ & Experienciador & $\begin{array}{l}\text { Processo } \\
\text { Mental }\end{array}$ & Fenômeno \\
\hline
\end{tabular}

A macrofigura que emerge dos processos relacionais no discurso de Carina Vitral é aquela de um mundo das relações dos participantes construindo uma relação dela com dois mundos opostos: o mundo do "nós" (UNE, estudantes e trabalhadores) e o mundo do "eles" (governo).

Constatamos então que, através da análise linguística, utilizando o sistema de transitividade realizado na metafunção ideacional da LSF de Halliday e Matthiessen (2014) nos textos da ex-presidente da UNE - Carina Vitral, emergiu duas macrofiguras. Na primeira, Carina Vitral é representada nos processos materiais como ator de resistência que faz frente ao governo vigente; na segunda, ela é representada nos processos relacionais, construindo uma relação dela com dois mundos opostos: o mundo do "nós" (UNE, estudantes e trabalhadores) e o mundo do "eles" (governo). O mundo do "nós" se expressa no sentido de uma aproximação com os estudantes e a população brasileira para juntar forças frente a um governo não legitimado. O mundo do "eles" refere-se ao governo apontando-o como conservador e opressor, pois vem aplicando práticas governamentais em que Carina Vitral e seu grupo não apoiam ou aceitam.

Nos textos analisados, Carina Vitral nos mostra que o seu posicionamento ideológico se alinha com as concepções de direita e esquerda de Bobbio (1995) em que a direita é prescritiva e a esquerda busca a ordem mas em nome da justiça. A esquerda também atribui ao Estado a responsabilidade de reduzir os índices de injus-

tiça e desigualdade social o que, para ela, não se aplica no atual governo.

Com isso, as formas de discurso político são produzidas por falantes individuais e pelas formas como eles "personalizam"as crenças grupais, subjacentes às propriedades mais particulares do discurso político. Assim, entre as convicções sociais e o discurso, precisamos de uma interface cognitiva que represente crenças, opiniões ou experiências pessoais que são ao mesmo tempo interpretações e avaliações pessoais de um evento, ou seja, o que realmente conhecemos como 'Esquerda e Direita' são representações sociais de determinados grupos sociais. Assim, notamos que em seu discurso, Carina Vitral tenta fazer justamente esse empoderamento das classes de estudantes e trabalhadores.

É importante esclarecer que as ocorrências dos demais processos foram significativamente baixas. Os processos mentais apareceram em $18 \%$ dos casos, os existenciais em $1 \%$, os verbais em $7 \%$ e não há ocorrências de processos comportamentais. Isso justifica o fato de não termos levado em conta esses processos na análise do discurso político da estudante Carina Vitral.

\section{CONSIDERAÇÔES FINAIS}

Chegamos ao final deste trabalho, em que nos dedicamos ao estudo do discurso político estudantil da União Nacional dos Estudantes (UNE). Nesta seção, faremos um breve balanço de nossa pesquisa, sobretudo levando em consideração os objetivos apresentados inicialmente. Cabe, em resumo, tentar expor o que pode ficar de nosso trabalho a título de contribuição em relação tanto ao objeto de estudo quanto ao nosso campo de investigação.

Buscamos aqui analisar o discurso político estudantil para mostrar como Carina Vitral se representa e representa seus interlocutores no contexto dos últimos acontecimentos políticos no Brasil, tais como o impeachment da ex-presidente Dilma Rousseff, o governo do 
UMA ANÁLISE DO DISCURSO POLÍTICO ESTUDANTIL DE CARINA VITRAL À LUZ DA LINGUÍSTICA SISTÊMICO-FUNCIONAL E DA ANÁLISE CRÍTICA DO DISCURSO

atual presidente Michel Temer, as prisões de membros do legislativo, a crise econômica do país e as manifestações populares que ocorreram nesse período. Tomamos como corpus um texto publicado em 04 de julho de 2016 pela estudante de economia da PUC-SP - Carina Vitral, ex-presidente da União Nacional dos Estudantes (UNE). Analisamos o texto por meio do sistema de transitividade da LSF que pudesse desvelar as representações dela e de seus interlocutores no texto, bem como as formações ideológicas em que o discurso atual da UNE se insere.

Acreditamos que o objetivo foi alcançado, uma vez que os dados obtidos ao longo do trabalho, como mostrou a discussão dos resultados, constataram basicamente a ocorrência de duas macrofiguras. Na primeira, Carina Vitral é representada nos processos materiais como ator de resistência que faz frente ao governo vigente; na segunda, ela é representada nos processos relacionais, construindo uma relação dela com dois mundos opostos: o mundo do "nós" (UNE, estudantes e trabalhadores) e o mundo do "eles" (governo).

Observamos ainda, que o discurso da Carina Vitral, de forma geral, filia-se a uma formação discursiva e ideológica de esquerda, entendida como aquela que defende primordialmente a igualdade, legitimando o papel social da UNE. Tendo em vista os resultados obtidos, acreditamos que esta pesquisa deixa uma contribuição, ainda que modesta, não apenas para o campo dos estudos da linguagem, mas também para a compreensão do movimento estudantil brasileiro de hoje, por meio de sua representante maior - a UNE.

Em suma, de acordo com o trabalho realizado, tudo indica que a UNE busca construir, no seu discurso, a imagem de uma entidade corajosa, que não se abala ou se atemoriza diante de injustiças ou de violências e que luta por um Brasil melhor, porém sem ferir princípios democráticos. Procura, desse modo, tal como foi no passado, colocar-se como um ator social importante e transformador.

\section{REFERÊNCIAS}

BOBBIO, N. Direita e esquerda: razões e significados de uma distinção política. 1. ed. São Paulo: Editora da Universidade Estadual Paulista, 1995. Tradução Marco Aurélio Nogueira.

DESOUZA, V. F. Power relations in Padre Cícero's epistolary political discourse: an investigation in the light of Systemic- Functional Grammar and Critical Discourse Analysis. Tese (Doutorado em Letras/Inglês e Literatura Correspondente) - Universidade Federal de Santa Catarina, Florianópolis, 2011. 173f.

DESOUZA, V. F. O lugar do conceito de ideologia na análise do discurso político $(\mathrm{adp})$ : uma proposta à luz da análise crítica do discurso (acd). Letras, v. 25, n. 50, p. 421-432, 2015.

FAIRCLOUGH, N. Discourse and social change. 1. ed. USA: Blackwell publishing inc., 2003.

FUZER, C.; CABRAL, S. R. S. Introdução à gramática sistêmico-funcional em língua portuguesa. 1. ed. Campinas: Mercado de Letras, 2014.

HALLIDAY, M. K. A.; MATTHIESSEN, C. M. I. M. An Introduction to Functional Grammar. 3. ed. London: Arnold, 2004.

An Introduction to Functional Grammar. 4. ed. London: Arnold, 2014.

LIMA-LOPES, R. E. Estudos de Transitividade em Língua Portuguesa: o perfil do gênero cartas de venda. Dissertação (Mestrado em Letras) — Pontíficia Universidade Católica de São Paulo, São Paulo, 2001.

Praxedes Filho, P. H. L. A corpora-based study of the development of EFL brazilian learners' interlanguage: from simplification to complexification in the light of systemic-functional grammar. Tese (Doutorado em Letras) Universidade Federal de Santa Catarina, Programa de Pós-graduação em Letras/Inglês e Literatura Correspondente, Florianópolis, 2007. 406f.

TAVEIRA, V. D. R. Conhecendo o discurso da une nos dias atuais: o éthos em foco. Dissertação (Mestrado em Letras) - Universidade Federal de Minas Gerais, Minas Gerais, 2013.

Van Dijk, T. A. What is Political Discourse Analysis? Belgian journal of linguistics. [S.1.], 1997.

Ideology: A multidisciplinary approach. 1. ed. London: Sage, 1998.

VITRAL, C. Carina e o tamanho do

Golpe na Educação. 2016. Disponível em: $<$ https://www.conversaafiada.com.br/brasil/ carina-e-o-tamanho-do-golpe-na-educacao > Acesso em: 10 nov 2016. 